\title{
Acyclic Coloring on Double Star Graph Families
}

\author{
R.Arundhadhi \\ Asst.Professor \\ Dept.of Mathematics, \\ D.G.Vaishnav college, \\ Chennai.
}

\author{
R.Sattanathan Ph.d \\ Head \&Professor, \\ Dept.of Mathematics, \\ D.G.Vaishnav college, \\ Chennai.
}

\begin{abstract}
The purpose of this study is to find the acyclic chromatic number for central graph, middle graph, total graph and line graph of Double star graph $\mathrm{K}_{1, \mathrm{n}, \mathrm{n}}$, denoted by $\mathrm{C}\left(\mathrm{K}_{1, \mathrm{n}, \mathrm{n}}\right)$, $\mathrm{M}\left(\mathrm{K}_{1, \mathrm{n}, \mathrm{n}}\right), \mathrm{T}\left(\mathrm{K}_{1, \mathrm{n}, \mathrm{n}}\right)$ and $\mathrm{L}\left(\mathrm{K}_{1, \mathrm{n}, \mathrm{n}}\right)$ respectively. Vernold vivin (et.al.,2011) [ 9 ], have proved that the star chromatic number and equitable chromatic number of these graphs are same. We discuss the relationship between the acyclic and star chromatic number of these graphs.
\end{abstract}

\section{Keywords}

Central graph, middle graph, total graph, line graph and acyclic coloring.

\section{INTRODUCTION}

Let $\mathrm{G}$ be a finite, undirected graph with no loops and multiple edges. Let $\mathrm{G}$ be a graph with vertex set $\mathrm{V}(\mathrm{G})$ and edge set $\mathrm{E}(\mathrm{G})$. The middle graph(Michalak,1981) of $\mathrm{G}$,denoted by $\mathrm{M}(\mathrm{G})$, is defined as follows. The vertex set of $\mathrm{M}(\mathrm{G})$ is $\mathrm{V}(\mathrm{G}) \mathrm{UE}(\mathrm{G})$. Two vertices $\mathrm{v}, \mathrm{w}$ in the vertex set of $\mathrm{M}(\mathrm{G})$ are adjacent in $\mathrm{M}(\mathrm{G})$ if one of the following holds.

1. $v, w$ are in $V(G)$ and $v$ is adjacent to $w$ in $G$.

2. $v$ is in $V(G)$ and $w$ is in $E(G)$ and $v, w$ are incident in G.

The central graph (Vernold et al., 2009 a,b) of G, denoted by $\mathrm{C}(\mathrm{G})$, is the graph obtained from $\mathrm{G}$ by subdividing each edge exactly once and joining all the non-adjacent vertices of $\mathrm{G}$.

The total graph (Michalak,1981; Harary 1969) of G,denoted by $T(G)$, is defined as follows. The vertex set of $T(G)$ is $\mathrm{V}(\mathrm{G}) \mathrm{UE}(\mathrm{G})$ and any two vertices $\mathrm{v}, \mathrm{w}$ in this set are adjacent in $\mathrm{T}(\mathrm{G})$ if one of the following holds.

1. $v, w$ are in $V(G)$ and $v$ is adjacent to $w$ in $G$.

2. $v, w$ are in $E(G)$ and $v, w$ are adjacent in $G$.

3. $v$ is in $V(G)$, w is in $E(G)$ and $v, w$ are incident in $G$.

The line graph (Harary,1969) of $\mathrm{G}$, denoted by $\mathrm{L}(\mathrm{G})$, is the graph with vertices are the edges of $\mathrm{G}$ and two vertices of $\mathrm{L}(\mathrm{G})$ are adjacent whenever, the corresponding edges of $\mathrm{G}$ are adjacent. Double star $\mathrm{K}_{1, \mathrm{n}, \mathrm{n}}$, is a tree obtained from the star $\mathrm{K}_{1, \mathrm{n}}$ by adding a new pendent edge of the existing $\mathrm{n}$ pendent vertices. It has $2 n+1$ vertices and $2 n$ edges.

The notion of acyclic chromatic number and star chromatic number were introduced by Grunbaum(1973). An acyclic coloring of a graph $\mathrm{G}$ is a proper coloring such that the sub graph induced by two colors $\alpha, \beta$ is a forest. The minimum number of colors necessary to acyclically color $\mathrm{G}$ is called the acyclic chromatic number and is denoted by $\mathrm{a}(\mathrm{G})$. A star coloring of a graph $\mathrm{G}$ is a proper vertex coloring in which every path on four vertices uses atleast three distinct colors. The star chromatic number, $X_{S}(G)$, of $G$, is the least number of colors needed to star color G. Vernold vivin(et al.,2011) have derived the following results[9] for the Double star graph families.

$$
\begin{aligned}
& \text { 1. } X_{S}\left(M\left[K_{1, n, n}\right]\right)=n+1 . \\
& \text { 2. } X_{S}\left(C\left[K_{1, n, n}\right]\right)=2 n+1 . \\
& \text { 3. } X_{S}\left(T\left[K_{1, n, n}\right]\right)=n+1 . \\
& \text { 4. } X_{S}\left(L\left[K_{1, n, n}\right]\right)=n .
\end{aligned}
$$

In the following chapters, we have derived the acyclic chromatic number for the Double star graph.

Let $\mathrm{v}$ be the root vertex of $\mathrm{K}_{1, \mathrm{n}, \mathrm{n}}$ and $\mathrm{v}_{1}, \mathrm{v}_{2}, \ldots, \mathrm{v}_{\mathrm{n}}$ be the vertices joined to the vertex $\mathrm{v}$ and $\mathrm{w}_{1}, \mathrm{w}_{2}, \ldots, \mathrm{w}_{\mathrm{n}}$ be the $\mathrm{n}$ pendent vertices of $\mathrm{K}_{1, \mathrm{n}, \mathrm{n}}$. Let $\mathrm{e}_{1}, \mathrm{e}_{2}, \ldots, \mathrm{e}_{\mathrm{n}}$ be the newly introduced vertices on the edge joining $\mathrm{v}$ and $\mathrm{v}_{\mathrm{i}}(\mathrm{i}=1$ to $\mathrm{n})$ and $\mathrm{s}_{1}, \mathrm{~s}_{2}, \ldots, \mathrm{s}_{\mathrm{n}}$ be the newly added vertices on the edge joining $\mathrm{v}_{\mathrm{f}}$ and $\mathrm{w}_{\mathrm{i}}$.

\section{ACYCLIC COLORING OF $M\left(K_{1, n, n}\right)$}

\subsection{Theorem}

For any Double star graph $\mathrm{K}_{1, \mathrm{n}, \mathrm{n}}$, the acyclic chromatic number of $\mathrm{M}\left(\mathrm{K}_{1, \mathrm{n}, \mathrm{n}}\right)$ is given by

$\mathrm{a}\left(\mathrm{M}\left[\mathrm{K}_{1, \mathrm{n}, \mathrm{n}}\right]\right)=\mathrm{n}+1, \mathrm{n} \geq 3$.

Proof:

By the definition of middle graph, $M\left[K_{1, n, n}\right]$ has the following structural properties.

1. $<\mathrm{v}, \mathrm{e}_{\mathrm{k}} ; \mathrm{k}=1$ to $\mathrm{n}>$ form a clique of order $\mathrm{n}+1$.

2. $\mathrm{e}_{\mathrm{i}}$ and $\mathrm{s}_{\mathrm{i}}$ are adjacent.

Now, consider the coloring $\mathrm{C}$ of $\mathrm{M}\left(\mathrm{K}_{1, \mathrm{n}, \mathrm{n}}\right)$ as follows. Assign $C_{i}$ to $e_{i}, i=1$ to $n$ and $c_{n+1}$ to $v$. Assign $c_{i+1}$ to $s_{i}, i=1$ to $n-1$ and $c_{1}$ to $s_{n}$. Now, we show that $C$ is acyclic.

Case(i). As $<v, e_{i} ; i=1$ to $n>$ form a clique of order $n+1$, it has no bicolored cycle. Consider $\mathrm{c}_{\mathrm{n}+1}$ and $\mathrm{c}_{\mathrm{i}}(1 \leq \mathrm{i} \leq \mathrm{n})$. The induced sub graph of these color classes contains only bicolored path of length atmost 2.( eg. $\left.\mathrm{e}_{\mathrm{i}} \mathrm{v}_{\mathrm{i}} \mathrm{v}_{\mathrm{i}-1} \mathrm{~S}_{\mathrm{i}-1} \mathrm{~W}_{\mathrm{i}-1}\right)$ and hence $\mathrm{M}\left(\mathrm{K}_{1, \mathrm{n}, \mathrm{n}}\right)$ has no bicolored $\left(\mathrm{c}_{\mathrm{i}}-\mathrm{c}_{\mathrm{n}+1}\right)$ cycle in the coloring $\mathrm{C}$. 


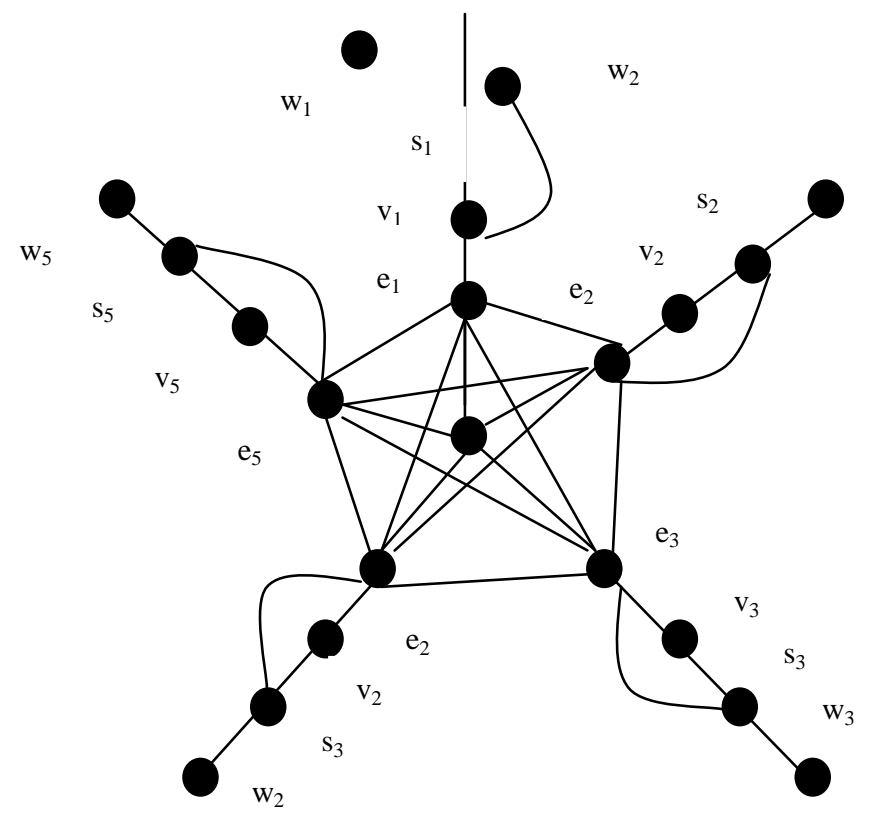

Figure.1 . a $\left(M\left[K_{1,5,5}\right]\right)=6$.

\section{ACYCLIC COLORING OF C[K $1, n, n]$}

\subsection{Theorem}

The acyclic chromatic number of $\mathrm{C}\left[\mathrm{K}_{1, \mathrm{nn}, \mathrm{n}}\right]$ is

$$
\mathrm{a}\left(\mathrm{C}\left[\mathrm{K}_{1, \mathrm{n}, \mathrm{n}}\right]\right)=2 \mathrm{n}, \mathrm{n} \geq 3 \text {. }
$$

Proof:

By the definition of central graph, $C\left[\mathrm{~K}_{1, \mathrm{n}, \mathrm{n}}\right]$ has the following structuralcharacteristics.

1. $\left\langle\mathrm{v}_{\mathrm{i}} ; \mathrm{i}=1\right.$ to $\mathrm{n}>$ form a clique of order $\mathrm{n}$.

2. $\left\langle\mathrm{v}, \mathrm{w}_{\mathrm{i}} ; \mathrm{i}=1\right.$ to $\mathrm{n}>$ form a clique of order $\mathrm{n}+1$.

3. $<v_{i}, w_{j} ; j=1$ to $n$ and $j \neq i>$ form a clique of order $n$.

4. $\left\{\mathrm{e}_{\mathrm{i}} ; \mathrm{i}=1\right.$ to $\left.\mathrm{n}\right\}$ and $\left\{\mathrm{s}_{\mathrm{i}} ; \mathrm{i}=1\right.$ to $\left.\mathrm{n}\right\}$ are independent sets.

Now, consider the coloring of $\mathrm{C}\left[\mathrm{K}_{1, \mathrm{n}, \mathrm{n}}\right]$ as follows.

Assign $c_{i}$ to $w_{i}, i=1$ to $n$ and $c_{n+1}$ to $v$. Assign $c_{n+1}$ to $s_{i}, i=1$ to n. Assign $c_{2}$ to $e_{i}, i=1$ to $n$ and $c_{1}$ to $v_{1}$. If we assign $c_{i}$ to $v_{i}$ for any $\mathrm{i}=2$ to $\mathrm{n}$, then $\mathrm{v}_{1} \mathrm{v}_{\mathrm{i}} \mathrm{w}_{1} \mathrm{w}_{\mathrm{i}} \mathrm{v}_{1}$ will form a bicolored $\left(\mathrm{c}_{1}-\mathrm{c}_{\mathrm{i}}\right)$ cycle. Hence, assign $c_{n+i}$ to $v_{i}, i=2$ to $n$. we can show that the above coloring is acyclic by the following analysis.

As the path $\mathrm{ve}_{\mathrm{i}} \mathrm{v}_{\mathrm{i}}(\mathrm{i}=1$ to $\mathrm{n})$ is colored with three colors, it can not be a part of any bicolored cycle. Similarly, the path $\mathrm{v}_{\mathrm{i}} \mathrm{S}_{\mathrm{i}} \mathrm{w}_{\mathrm{i}}($ $\mathrm{i}=2$ to $\mathrm{n}$ ) can not be a part of any bicolored cycle. So, consider $\mathrm{v}_{1} \mathrm{~s}_{1} \mathrm{w}_{1}$, a bicolored $\left(\mathrm{c}_{1}-\mathrm{c}_{\mathrm{n}+1}\right)$ path. As $\mathrm{v}$ and $\mathrm{v}_{1}$ are non adjacent in $\mathrm{C}\left[\mathrm{K}_{1, \mathrm{n}, \mathrm{n}}\right]$, it is only a bicolored path, but not cycle.

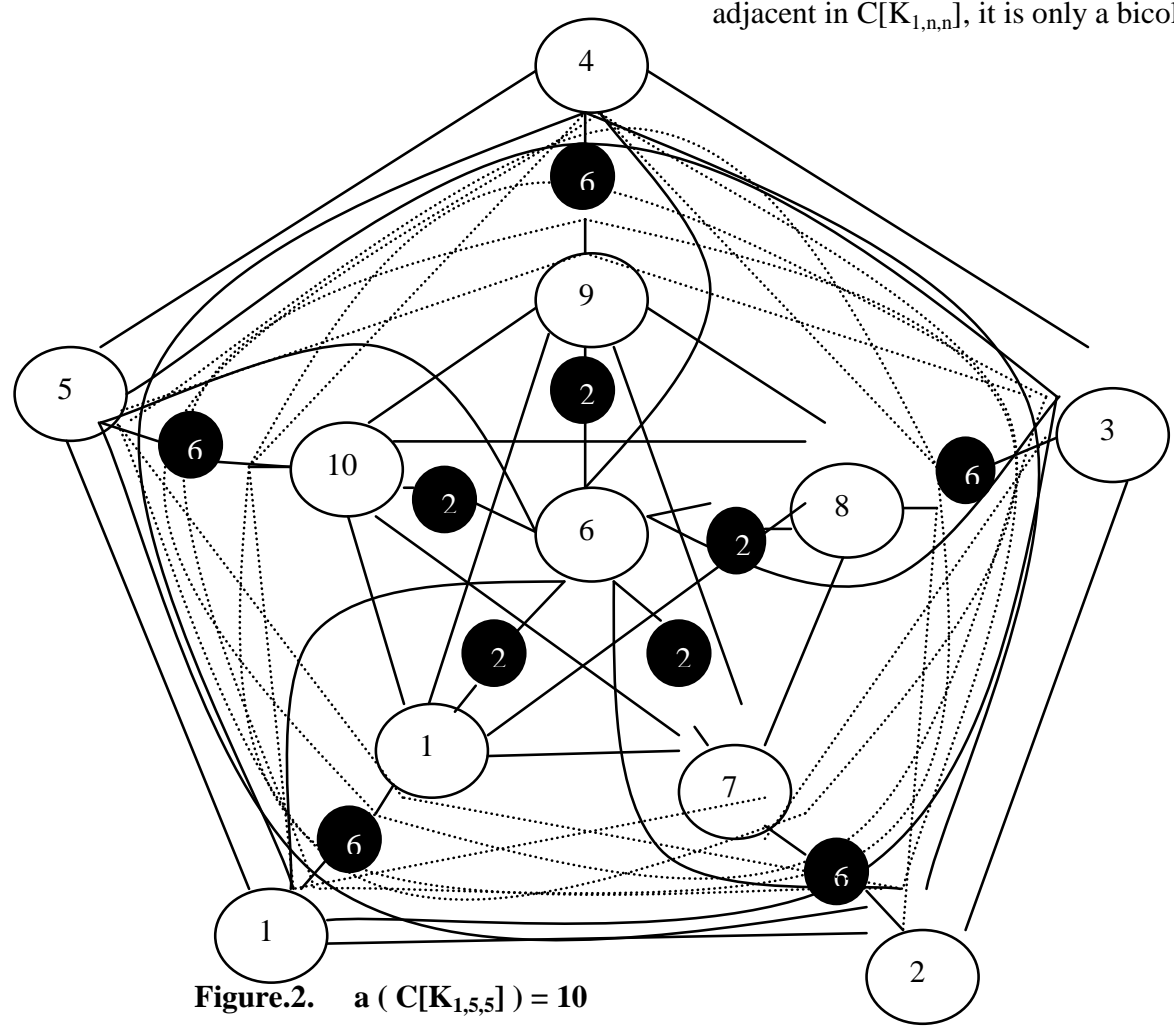

Case(ii). Consider $\mathrm{c}_{\mathrm{j}}$ and $\mathrm{c}_{\mathrm{k}}(1 \leq \mathrm{j}<\mathrm{k} \leq \mathrm{n})$. The color classes of $\mathrm{c}_{\mathrm{j}}$ is $\left\{\mathrm{e}_{\mathrm{j}}, \mathrm{s}_{\mathrm{j}-1}\right\}$ and that of $\mathrm{c}_{\mathrm{k}}$ is $\left\{\mathrm{e}_{\mathrm{k}}, \mathrm{s}_{\mathrm{k}-1}\right\}$. The induced sub graph of these color classes contains only the bicolored path, $e_{k} e_{j} s_{k}$ when $k=j+1$ and the edge $e_{k} e_{j}$ when $k>j+1$. In both cases, $\mathrm{M}\left[\mathrm{K}_{1, \mathrm{n}, \mathrm{n}}\right]$ has no bicolored $\left(\mathrm{c}_{\mathrm{j}}-\mathrm{c}_{\mathrm{k}}\right)$ cycle. So, the coloring $\mathrm{C}$ is acyclic and therefore,

$\mathrm{a}\left[\mathrm{M}\left(\mathrm{K}_{1, \mathrm{n}, \mathrm{n}}\right)\right]=\mathrm{n}+1, \mathrm{n} \geq 3$.
Thus, $\mathrm{C}\left[\mathrm{K}_{1, \mathrm{n}, \mathrm{n}}\right]$ has no bicolored cycle in the above coloring. Therefore,

$$
\mathrm{a}\left(\mathrm{C}\left[\mathrm{K}_{1, \mathrm{n}, \mathrm{n}}\right]\right)=2 \mathrm{n}, \mathrm{n} \geq 3 \text {. }
$$

\section{ACYCLIC COLORING OF T[K $1, n, n]$}

\subsection{Theorem}

For any Double star graph $\mathrm{K}_{1, \mathrm{n}, \mathrm{n}}$,

$$
\text { A }\left(\mathrm{T}\left[\mathrm{K}_{1, \mathrm{n}, \mathrm{n}}\right]\right)=\mathrm{n}+1, \mathrm{n} \geq 3 \text {. }
$$


Proof:

In $\mathrm{T}\left[\mathrm{K}_{1, \mathrm{n}, \mathrm{n}}\right]$,

1. $\left\langle\mathrm{v}, \mathrm{e}_{\mathrm{i}} ; \mathrm{i}=1\right.$ to $\mathrm{n}>$ form a clique of order $\mathrm{n}+1$.

2. $\mathrm{v}$ and $\mathrm{v}_{\mathrm{i}}(\mathrm{i}=1$ to $\mathrm{n}), \mathrm{v}_{\mathrm{i}}$ and $\mathrm{w}_{\mathrm{i}}(\mathrm{i}=1$ to $\mathrm{n})$ are adjacent.

3. $e_{i}$ and $s_{i}(i=1$ to $n)$ are adjacent.

Now, color the vertices of $\mathrm{T}\left[\mathrm{K}_{1, \mathrm{n}, \mathrm{n}}\right]$ as follows

Assign $c_{i}$ to $e_{i}$ and $w_{i}(i=1$ to $n)$ and $c_{n+1}$ to $v$. Assign $c_{i+1}$ to $\mathrm{v}_{\mathrm{i}}(\mathrm{i}=1$ to $\mathrm{n}-1)$ and $\mathrm{c}_{1}$ to $\mathrm{v}_{\mathrm{n}}$. Assign $\mathrm{c}_{\mathrm{n}+1}$ to $\mathrm{s}_{\mathrm{i}}(\mathrm{i}=1$ to $\mathrm{n})$. consider the following cases in order to show that the given coloring is acyclic.

Case(i)

Consider $c_{n+1}$ and $c_{i}(i=1$ to $n)$. In the induced sub graph of these color classes, we get only the bicolored path, $\mathrm{w}_{\mathrm{i}} \mathrm{s}_{\mathrm{i}} \mathrm{e}_{\mathrm{i}} \mathrm{V}$ $\mathrm{v}_{\mathrm{i}-1} \mathrm{~S}_{\mathrm{i}-1}$, not cycle. Therefore, $\mathrm{T}\left[\mathrm{K}_{1, \mathrm{n}, \mathrm{n}}\right]$ has no bicolored cycle in the given coloring.

\section{Case(ii)}

Consider $c_{i}$ and $c_{i+1}(i=1$ to $n-1)$. The induced sub graph of these color classes contains the bicolored path, $\mathrm{e}_{\mathrm{i}+1} \mathrm{e}_{\mathrm{i}} \mathrm{v}_{\mathrm{i}} \mathrm{w}_{\mathrm{i}}$, but not cycle. So, $T\left[K_{1, n, n}\right]$ has no bicolored $\left(c_{i-}-c_{i+1}\right)$ cycle.

\section{Case(iii)}

Consider $c_{k}$ and $c_{j}$ where $1 \leq \mathrm{k}<\mathrm{j}-1 \leq \mathrm{n}$. The induced sub graph of these color classes contains the edge $e_{k} e_{j}$ and not any bicolored cycle.

So, the given coloring is acyclic. Therefore,

$$
\mathrm{a}\left(\mathrm{T}\left[\mathrm{K}_{1, \mathrm{n}, \mathrm{n}}\right]\right)=\mathrm{n}+1, \mathrm{n} \geq 3
$$

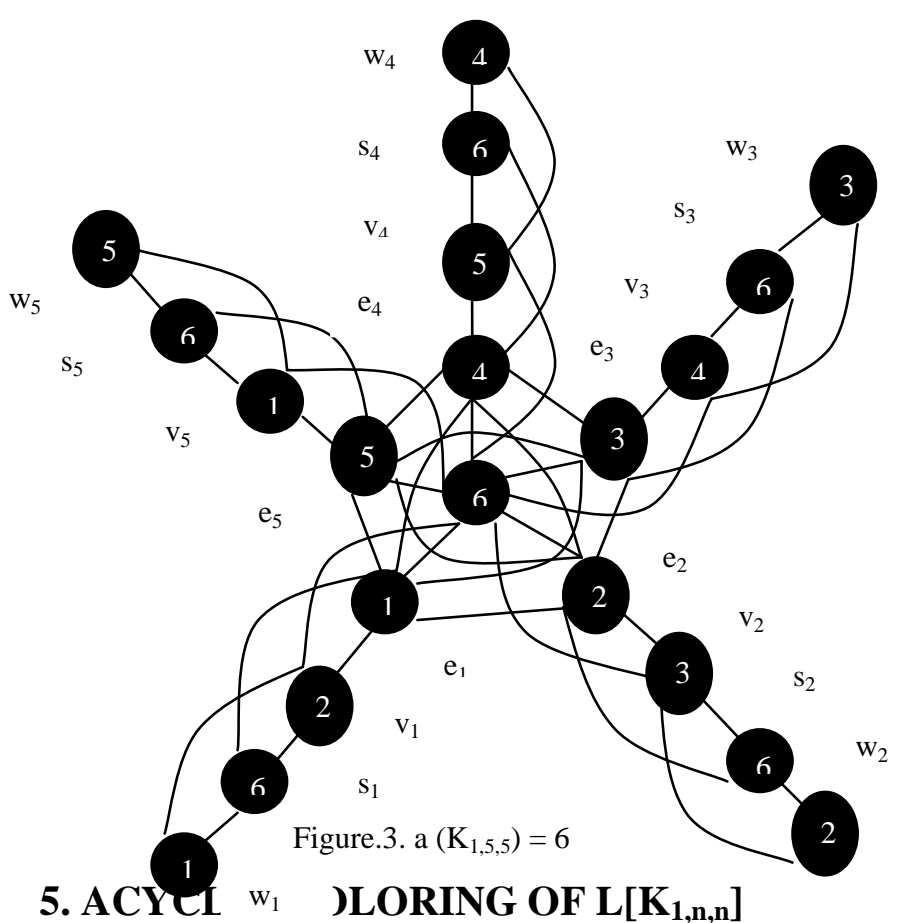

\subsection{Theorem}

For any Double star graph $\mathrm{K}_{1, \mathrm{n}, \mathrm{n}}$,

$\mathrm{a}\left(\mathrm{L}\left[\mathrm{K}_{1, \mathrm{n}, \mathrm{n}}\right]\right)=\mathrm{n}$.

Proof:

In $\mathrm{L}\left[\mathrm{K}_{1, \mathrm{n}, \mathrm{n}}\right]$,
1. $\left\langle e_{i} ; i=1\right.$ to $n>$ form a clique of order $n$

2. $e_{i} s_{i}$ is the pendent edge at $e_{i}$

Now color $\mathrm{L}\left[\mathrm{K}_{1, \mathrm{n}, \mathrm{n}}\right]$ as follows:

Assign $c_{i}$ to $e_{i}, i=1$ to $n$ and $c_{i-1}$ to $s_{i}, i=2$ to $n-1$ and $c_{n}$ to $s_{1}$. The induced sub graph of any two color classes $c_{i}$ and $c_{j}$ contains a bicolored path $e_{i} e_{j} s_{j}$ if $|i-j|=1$ and the edge $e_{i} e_{j}$ if $|i-j|>1$. So, the coloring is acyclic and therefore,

$\mathrm{a}\left(\mathrm{L}\left[\mathrm{K}_{1, \mathrm{n}, \mathrm{n}}\right]\right)=\mathrm{n}$.

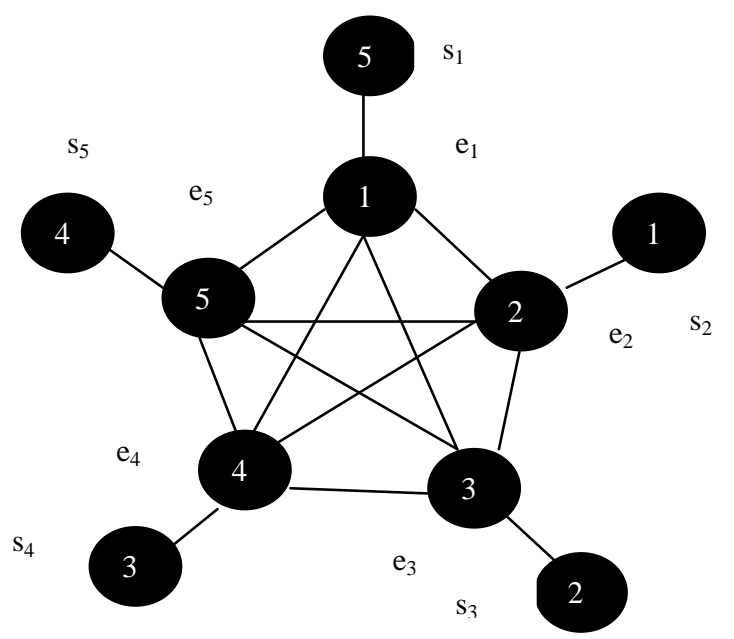

Figure $4 . \mathrm{a}\left(\mathrm{L}\left[\mathrm{K}_{1,5,5}\right]\right)=5$

\section{Conclusion}

Using the result of the study and the result of Vernold [9 ], we have the following results:

1. $X_{\mathrm{s}}\left\{M\left[\mathrm{~K}_{1, \mathrm{n}, \mathrm{n}}\right]\right\}=\mathrm{n}+1=\mathrm{a}\left(\mathrm{M}\left[\mathrm{K}_{1, \mathrm{n}, \mathrm{n}}\right]\right\}$.

2. $\mathrm{X}_{\mathrm{S}}\left(\mathrm{C}\left[\mathrm{K}_{1, \mathrm{n}, \mathrm{n}}\right]\right\}=2 \mathrm{n}+1=\mathrm{a}\left(\mathrm{C}\left[\mathrm{K}_{1, \mathrm{n}, \mathrm{n}}\right]\right\}+1$.

3. $\mathrm{X}_{\mathrm{S}}\left(\mathrm{T}\left[\mathrm{K}_{1, \mathrm{n}, \mathrm{n}}\right]\right\}=\mathrm{n}+1=\mathrm{a}\left(\mathrm{T}\left[\mathrm{K}_{1, \mathrm{n}, \mathrm{n}}\right]\right\}$.

4. $\mathrm{X}_{\mathrm{S}}\left(\mathrm{L}\left[\mathrm{K}_{1, \mathrm{n}, \mathrm{n}}\right]\right\}=\mathrm{n}=\mathrm{a}\left(\mathrm{L}\left[\mathrm{K}_{1, \mathrm{n}, \mathrm{n}}\right]\right\}$.

\section{REFERENCES}

[1] B.Grunbaum, 'Acyclic coloring of planar graph', Israel J.Mat, 14,3,390-408,1973.

[2] D.Michalak, 'On middle and total graphs with coarseness number equal 1', Graph Theory, 1018,139-150,1981.

[3] K.Thilagavathy, Vernold Vivin.J and Akbar Ali.M,'On Harmonious coloring of central graphs', Advances and application in Discrete mathematics,2,17-33(2009).

[4] M.Venkatachalam, Vernold Vivin.J and Akbar Ali M. 'A note on achromatic coloring of star graph families', 23,3,251-255(2009).

[5] M.Venkatachalam, Vernold Vivin.J and Akbar Ali M 'Achromatic coloring on double star graph families', Int.J.Math.Comb.,3,71-81\{2009a).

[6] M.Venkatachalam, Vernold Vivin.J and Akbar Ali M. 'A note on achromatic coloring of star graph families', Filomat, 23,251-255(2009b). 
[7] K.Thilagavathi, D.Vijayalakshmi and Roopesh, 'B-coloring of central graphs', International journal of computer applications, vol 3,11,27-29\{2010).

[8] K.Thilagavathi and Shahnas Banu,'Acyclic coloring of star graph families', International journal of computer applications, vol 7,2,31-33 (2010).

[9] M.Venkatachalam, Vernold Vivin.J and N. Mohanapriya 'Star coloring on double star graph families', J.Modern Mathe. Stat., 5,1,33-36(2011).
[10] R.Arundhadhi and R.Sattanathan, 'Acyclic coloring of wheel graph families' Ultra scientist of physical sciences, vol 23, 3(A), 709-716(2011).

[11] R.Arundhadhi and R.Sattanathan, 'Acyclic coloring of central graphs', International journal of computer applications, vol 38,12,8 55-57(2012).

[12] R.Arundhadhi and R.Sattanathan, 'Acyclic coloring of central graph of path on $n$ vertices and central graph of fan graph families', International conference on Mathematics in Engineering and Business-2012(under submission). 